\title{
ИЗУЧЕНИЕ МОРФОФУНКЦИОНАЛЬНЫХ ИЗМЕНЕНИЙ ФОЛЛИКУЛОВ ЩИТОВИДНОЙ ЖЕЛЕЗЫ КРЫС В НОРМЕ И ПРИ ГИПОТИРЕОЗЕ ПОСЛЕ ВОЗДЕЙСТВИЯ СРЕДНЕИНТЕНСИВНОГО ЛАЗЕРНОГО ИЗЛУЧЕНИЯ
}

\author{
И. В. Смелова ${ }^{\square}$, Е. С. Головнева²
}

'Многопрофильный центр лазерной медицины, Челябинск

2 Южно-Уральский государственный медицинский университет, Челябинск

Проблема гипотиреоза в последнее время не теряет своей актуальности. При лечении тиреопатий успешно используется лазерное облучение щитовидной железы. Эффективность лазерного воздействия зависит от применяемой дозы излучения. Изменение формы и объема структурно-функциональных единиц органа (тиреоцитов и фолликулов) является дозозависимым процессом и отражает их функциональное состояние, влияющее на синтез, накопление и секрецию тиреоидных гормонов. Целью исследования было изучение влияния инфракрасного лазерного облучения средней интенсивности при суммарной плотности дозы с поверхности кожи 112 Дж/см² и 450 Дж/см² на морфофункциональное состояние тиреоцитов и фолликулов щитовидной железы в норме и при гипотиреозе. Эксперимент проведен на лабораторных крысах самцах. Показано, что лазерное воздействие изменяет состояние тиреоцитов и фолликулов как интактной щитовидной железы, так и при гипотиреозе. При сравнении эффектов двух изучаемых режимов лазерного воздействия на щитовидную железу с экспериментальным гипотиреозом повышение функции и регенеративных процессов железы отмечено при плотности дозы с поверхности кожи 112 Дж/см², и торможение при плотности дозы 450 Дж/см². Полученные результаты могут быть использованы для коррекции гипотиреоза в эксперименте.

Ключевые слова: тиреоцит, фолликул, ядерно-клеточное отношение, индекс накопления коллоида, лазерное излучение, щитовидная железа, гипотиреоз

$\triangle$ Для корреспонденции: Ирина Викторовна Смелова ул. Потемкина, д. 14, кв. 65, г. Челябинск, 454081; spiral.siv@mail.ru

Статья получена: 15.02.2018 Статья принята к печати: 20.03.2018

DOI: $10.24075 /$ vrgmu.2018.028

\section{THE STUDY OF MORPHOLOGICAL AND FUNCTIONAL CHANGES IN THE THYROID FOLLICLES OF HEALTHY RATS AND RATS WITH EXPERIMENTALLY INDUCED HYPOTHYROIDISM FOLLOWING EXPOSURE TO MEDIUM-POWER LASER RADIATION}

\author{
Smelova IV1凶, Golovneva ES ${ }^{2}$ \\ 'Multidisciplinary Center for Laser Medicine, Chelyabinsk \\ 2 South Ural State Medical University of Ministry of Health of Russia, Chelyabinsk
}

\begin{abstract}
Hypothyroidism remains a pressing concern. Laser irradiation is a widely used treatment option for patients with thyroid pathologies. Its efficacy depends on the applied dose. Changes in the form and volume of the structural components of the glands, such as thyrocytes and follicles, are dose-dependent and signal their functional state, which affects production, accumulation and secretion of thyroid hormones. The aim of our study was to explore the effect of infrared medium-power laser with total energy densities of $112 \mathrm{~J} / \mathrm{cm}^{2}$ and $450 \mathrm{~J} / \mathrm{cm}^{2}$ on the morphology and function of the thyroid and its follicles in health and hypothyroidism. The experiment was conducted in male rats. It was demonstrated that laser radiation affects the morphological state of thyrocytes and follicles of both intact animals and animals with experimentally induced hypothyroidism. Comparison of two laser regimens revealed that $112 \mathrm{~J} / \mathrm{cm}^{2}$ energies stimulated tissue regeneration and thyroid activity in general, whereas $450 \mathrm{~J} / \mathrm{cm}^{2}$ energies suppressed those processes. Our findings can be used to study hypothyroidism treatment options in the experimental setting.
\end{abstract}

Keywords: thyrocyte, follicle, nucleus/cell ratio, colloid accumulation index, laser, thyroid, hypothyroidism

$\triangle$ Correspondence should be addressed: Irina V. Smelova

Potemkina 14, kv. 65, Chelyabinsk, 454081; spiral.siv@mail.ru

Received: 15.02.2018 Accepted: 20.03.2018

DOI: 10.24075/brsmu.2018.028

Гипотиреоз - одно из наиболее распространенных эндокринных заболеваний. Взаимосвязь патологии щитовидной железы с нарушением функций различных органов и систем, а также несовершенство методов решения проблемы объясняет интерес врачей различных специальностей к данному вопросу [1]. Ведется активный поиск новых способов лечения, в том числе с использованием лазерных технологий. Приоритетное направление в коррекции субклинического гипотиреоза имеет низкоинтенсивная лазеротерапия [2, 3]. Наряду с этим разрабатываются методики на основе лазерного воздействия повышенной мощности для достижения терапевтических доз на глубине ткани $[4,5]$.

Щитовидная железа доступна прямому лазерному воздействию с поверхности тела. Лазерное облучение может изменять ее функцию, способствовать повышению 
выработки гормонов, улучшать микроциркуляцию и влиять на репарацию тканей органа, что успешно применяется при лечении гипотиреоза и аутоиммунных тиреоидитов [6-10]. Существует мнение, что воздействие фотонов света на строму железы способствует ее структурной перестройке [10], вызывая изменение высоты эпителия, формы и объема фолликулов.

До настоящего времени остается неизученным влияние плотности дозы среднеинтенсивного лазерного воздействия на функциональную активность щитовидной железы у животных в норме и животных с экспериментальным гипотиреозом.

Целью работы было изучение воздействия среднеинтенсивного инфракрасного лазерного облучения щитовидной железы на морфофункциональное состояние тиреоидного эпителия и фолликулов в норме и при экспериментальном гипотиреозе в зависимости от плотности дозы лазерной энергии.

\section{МАТЕРИАЛЫ И МЕТОДЫ}

Исследование проводилось на базе Южно-Уральского государственного медицинского университета и Многопрофильного центра лазерной медицины города Челябинска с 2016 по 2018 годы. Эксперимент выполнен на 78 беспородных половозрелых лабораторных крысах самцах, весом 200-220 г, содержавшихся в условиях вивария, в клетках по 2-3 особи ad libitum, на сбалансированном рационе и обычном световом режиме (день-ночь). Выбор особей-самцов обусловлен отсутствием у них гормональных колебаний, эструса. Опыты проведены с соблюдением норм и правил гуманного обращения с животными; в соответствии с «Правилами проведения работ с использованием экспериментальных животных», регламентированных в приложении к приказу МЗ СССР №755 от 12.09.77, и строгом соответствии с требованиями Хельсинской декларации Всемирной медицинской ассоциации 1964 г. с изменениями от 1975, 1983 и 1989 годов.

Животные были разделены на 6 групп:

1) интактные животные;

2) интактные животные, суммарная плотность дозы лазерного воздействия на щитовидную железу 112 Дж/см² (0,5 Bт, $45 \mathrm{c})$;

3) интактные животные, суммарная плотность дозь лазерного воздействия на щитовидную железу 450 Дж/см² (1,5 Вт, 60 c);

4) животные с экспериментальным гипотиреозом;

5) животные с экспериментальным гипотиреозом, суммарная плотность дозы лазерного воздействия на щитовидную железу 112 Дж/см² (0,5 Вт, 45 c);

6) животные с экспериментальным гипотиреозом; суммарная плотность дозы лазерного воздействия на щитовидную железу 450 Дж/см² (1,5 Вт, 60 с).

Гипотиреоз моделировали ежедневным пероральным введением 0,5 мл тиамазола в 0,9\% изотоническом растворе $\mathrm{NaCl}$, приготовленного из препарата «Мерказолил» («Акрихин», Россия) ex tempore, в дозе 25 мг/кг с помощью специального зонда в течение 21 суток [11]. Животным контрольной группы ежедневно перорально вводили 0,5 мл 0,9\% изотонического раствора в течение 21 суток. Оценку гипотиреоза проводили по клиническим признакам (изменению массы тела, аппетита, состояния шерсти, температуры), а также морфологическому состоянию щитовидной железы и уровню тиреоидных гормонов сыворотки.
Лазерное воздействие осуществляли аппаратом «ИРЭПолюс» (НТО «ИРЭ-Полюс», Россия), длина волны рабочего излучения 970 нм, в непрерывном режиме в течение пяти дней, начиная со следующего дня после окончания моделирования гипотиреоза (22-е сутки).

Выведение животных из эксперимента осуществляли под эфирным наркозом путем цервикальной дислокации через 1, 7, 30 суток после окончания облучения.

Материал для морфологического исследования забирали в 10\% раствор нейтрального формалина, затем готовили стандартные гистологические парафиновые срезы, которые окрашивали гематоксилином - эозином ( $\mathrm{pH}=2,0)$. Микроскопические исследования проводили на микроскопе «DMRXA» (Leica, Германия) при увеличении в 400 раз. Результаты анализировали с помощью компьютерной программы «ImageScope M», 2006 г. (Германия), совмещенной с микроскопом. Морфометрический анализ гистологических срезов заключался в определении высоты тиреоидного эпителия, минимального и максимального диаметра, площади фолликулов. Измерение высоты эпителия и размера фолликулов проводили по 10 полям зрения в каждом препарате. Для оценки функциональной активности щитовидной железы вычисляли показатель Брауна (индекса накопления коллоида) как отношение внутреннего диаметра фолликула к удвоенной высоте фолликулярного эпителия и ядерно-клеточный показатель - отношение площади ядра тиреоцита к площади клетки, выраженное в процентах.

Полученные данные анализировали при помощи компьютерных программ Microsoft Office Excel (2007 г.), SPSS Statistics 20 (2014 г.) непараметрическими методами с вычислением медианы, верхнего и нижнего квартилей. Для оценки значимости различий между группами сравнения использовали критерий Манна-Уитни. При вероятности ошибки $p<0,05$ различия в группах считались статистически значимыми.

\section{РЕЗУЛЬТАТЫ ИССЛЕДОВАНИЯ}

На анализируемых гистологических препаратах щитовидная железа животных контрольной группы имела дольчатое строение. Соединительнотканные перегородки между дольками хорошо выражены. Округлые и овальные фолликулы средних размеров, расположены компактно. Тиреоциты кубической формы с четкими контурами образуют один слой фолликулярного эпителия. Ядра клеток эпителия шаровидные, лежат у основания. Просвет фолликулов равномерно заполнен коллоидом розовофиолетового цвета, нередко пенистым по краям (рис. 1).

После моделирования гипотиреоза дольчатое строение щитовидной железы сохранилось. Объем стромы увеличился. Соединительнотканные перегородки между дольками стали более рыхлыми с участками очагового венозно-капиллярного полнокровия, эритростазами. Фолликулы уменьшились в размере, коллоид светлый, часто без окраски. Тиреоциты в некоторых полях зрения увеличены в объеме, имеют «пенистую" вакуолизированную бледноокрашенную цитоплазму. Имеются клетки с явлениями некробиоза, ядра у них бледноокрашенные, а часть клеток с полной утратой ядер (рис. 2).

При анализе данных, полученных в нашем исследовании, мы отмечали, что медикаментозное моделирование гипотиреоза способствует изменению стромальнопаренхиматозных характеристик щитовидной железы. Морфологически объем клетки увеличивался вследствие 
тяжелой гидропической и вакуольной дистросии. Цитоплазма этих клеток слабо воспринимала кислые красители и имела бледно-розовое окрашивание, в то время как в интактном контроле цитоплазма была однородной, гомогенной, оптически плотной, хорошо воспринимала кислые красители. В щитовидной железе с моделью гипотиреоза мы находили участки ткани с тяжелой дистроффией, вплоть до некробиозов и некрозов. Увеличение объема органа в целом происходило за счет отека. Показатель ядерноклеточного отношения уменьшался преимущественно за счет увеличения площади цитоплазмы тиреоцитов, изменение площади ядер было менее существенным.

При сравнении этих групп отмечалось статистически значимое изменение анализируемых структурных образований (табл. 1). Высота тиреоидного эпителия уменьшалась на ранних сроках (1 и 7 суток) и повышалась через 30 суток, а максимальный, минимальный диаметр и площадь фолликулов уменьшались через 7 и 30 суток. Показатели ядерно-клеточного отношения были меньше на всех сроках наблюдения, а индекс Брауна больше через 1 сутки и меньше через 30 суток по сравнению с контрольной группой (табл. 2).

После лазерного облучения щитовидной железы интактных животных при суммарной плотности дозы с поверхности кожи, равной 112 Дж/см², изменения в препаратах по всем срокам наблюдения были однотипные, различие проявлялось в сосудистой реакции. Отмечалось полнокровие сосудов, наиболее выраженное паретическое, через сутки. Структура щитовидной железы сохранялась. Некоторые фолликулы были увеличены в размере, коллоид яркорозовый, компактный. Высота тиреоидного эпителия достоверно увеличилась, а диаметры и площадь фолликулов уменьшились во всех группах (табл. 1). Ядерно-клеточное отношение увеличилось, а индекс Брауна уменьшился на всех сроках наблюдения (табл. 2).

Воздействие лазером на щитовидную железу интактных животных при суммарной плотности дозы с поверхности кожи, равной 450 Дж/см², вызывало выраженное

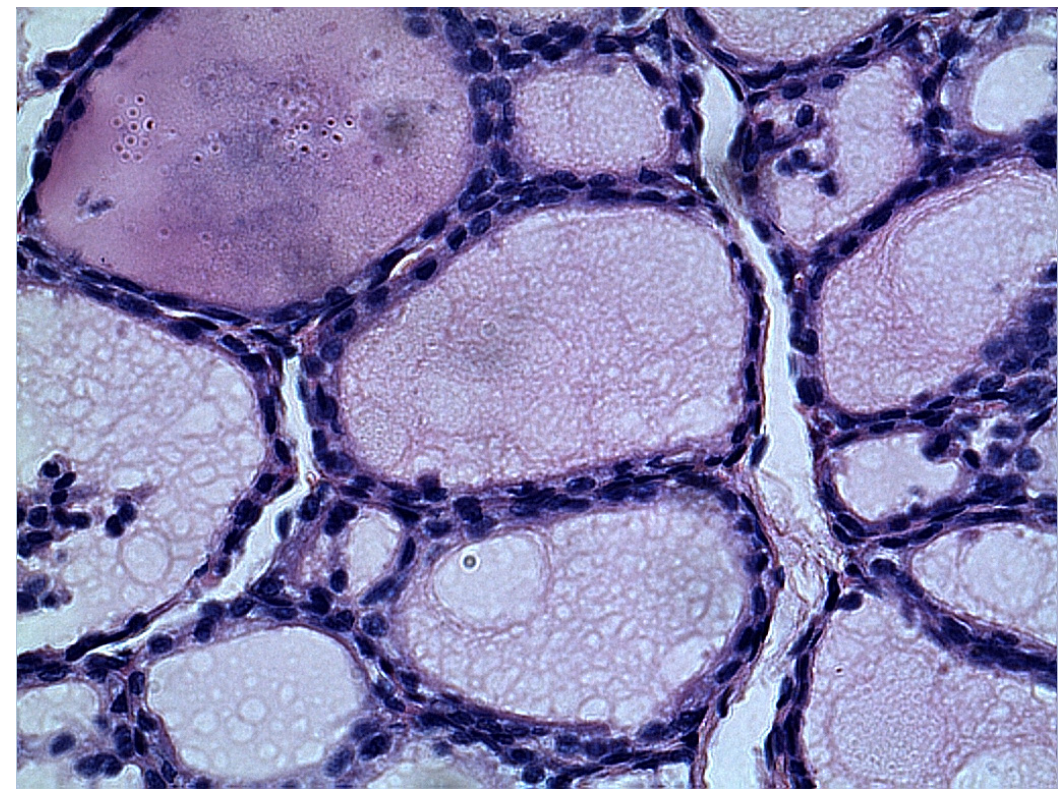

Рис. 1. Интактная щитовидная железа. Окраска: гематоксилин-эозин; ув. ×400

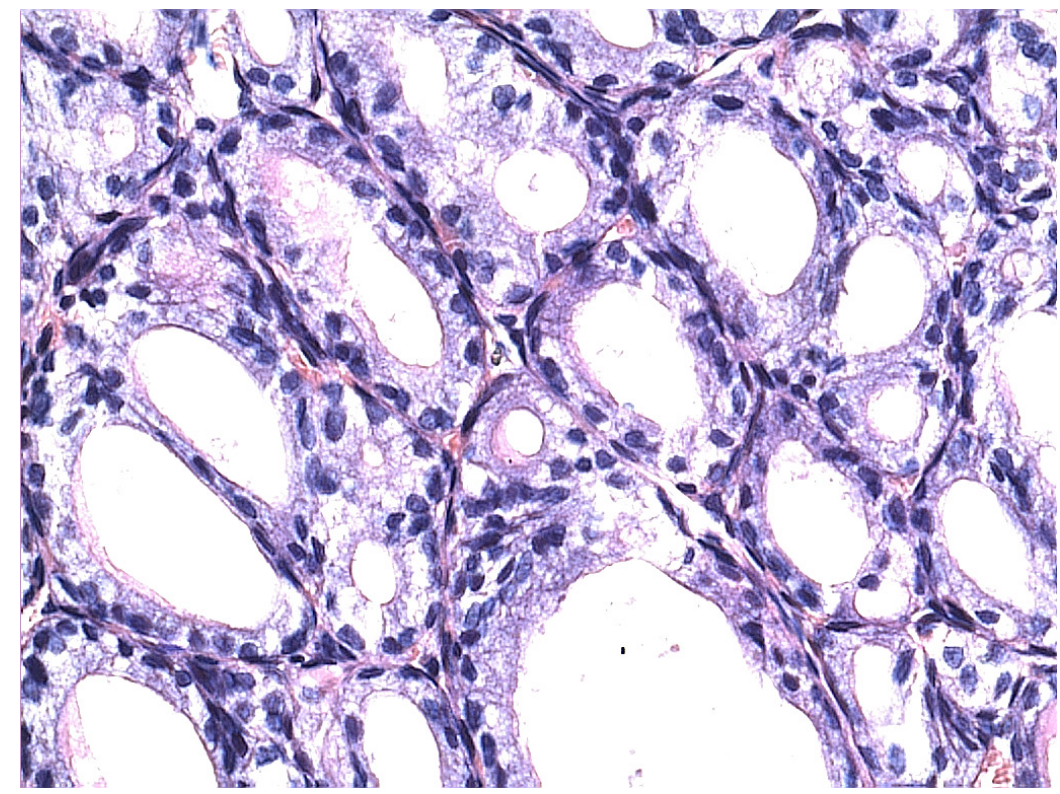

Рис. 2. Гипотиреоз. Окраска: гематоксилин-эозин; ув. ×400 
паретическое полнокровие органа на ранних сроках (1 и 7 сутки). После воздействия цитоплазма тиреоцитов была несколько набухшей, мелкозернистой. Группы клеток имели форму, близкую к цилиндрической, кроме того мы наблюдали тиреоциты кубической формы, розовый мелкозернистый коллоид, однородные фолликулы. Через 30 суток после облучения структура железы была сопоставима с группой сравнения, но коллоид оставался мелкозернистым.

Статистически значимое повышение высоты тиреоидного эпителия отмечали через 1 и 30 суток. Увеличивались минимальный, максимальный диаметр и площадь фолликулов на ранних сроках наблюдения ( 1 и 7 сутки) с последующим уменьшением значений ниже исходного уровня к концу 30 суток. Индекс Брауна достоверно повышался через 7 суток и уменьшался через 30 суток.

После окончания лазерного воздействия в дозе 112 Дж/см² на щитовидную железу животных с моделью гипотиреоза сохранилось дольчатое строение органа с хорошо развитой стромой, большим количеством кровеносных сосудов (рис. 3). Фолликулы были средними и крупными при заборе материала через 1 сутки и преимущественно мелкими через 7 и 30 суток. Фолликулярный эпителий был кубической и призматической формы

Таблица 1. Сравнительная характеристика групп животных по высоте эпителия, диаметру и площади фолликулов

\begin{tabular}{|c|c|c|c|c|c|}
\hline \multicolumn{2}{|c|}{ Группы } & $\begin{array}{l}\text { Высота эпителия } \\
\text { (мкм) }\end{array}$ & $\begin{array}{c}\text { Максимальный диаметр } \\
\text { фолликула (Мкм) }\end{array}$ & $\begin{array}{c}\text { Минимальный диаметр } \\
\text { фолликула (МКм) }\end{array}$ & $\begin{array}{c}\text { Площадь фолликула } \\
\left(\text { (мкм²) }^{2}\right.\end{array}$ \\
\hline \multicolumn{2}{|c|}{ Группа 1: интактные животные } & $5,41(4,31 ; 6,06)^{\# 1}$ & $67,25(51,83 ; 85,20)^{\# 1}$ & $39,85(28,00 ; 65,23)^{\# 1}$ & $1936,55(1162,15 ; 4469,65)^{\# 1}$ \\
\hline \multirow{3}{*}{$\begin{array}{l}\text { Группа 2: интактные } \\
\text { животные, суммарная } \\
\text { плотность дозы } \\
112 \text { Дж/см² }\end{array}$} & через 1 сутки & $8,29(7,49 ; 9,47)^{\# 0}$ & $53,30(40,10 ; 71,13)^{\# 0}$ & $33,85(26,58 ; 39,60)^{\# 0}$ & $1376,25(847,14 ; 2150,53)^{* 0}$ \\
\hline & через 7 суток & $6,46(6,05 ; 6,89)^{* 0}$ & $41,15(33,23 ; 56,53)^{\# 0}$ & $29,25(22,40 ; 32,95)^{\# 0}$ & $947,22(679,17 ; 1468,73)^{\# 0}$ \\
\hline & через 30 суток & $6,25(5,54 ; 6,94)^{* 0}$ & $46,00(33,03 ; 62,98)^{*}$ & $30,80(25,60 ; 47,48)^{\#}$ & $1123,71(682,97 ; 2436,70)^{\#}$ \\
\hline \multirow{3}{*}{$\begin{array}{l}\text { Группа 3: интактные } \\
\text { животные, суммарная } \\
\text { плотность дозы } \\
450 \text { Дж/см² }\end{array}$} & через 1 сутки & $7,78(6,74 ; 9,27)^{\# 0}$ & $144,00(61,25 ; 232,00)^{\# 0}$ & $89,80(46,05 ; 151,00)^{\# 0}$ & $10329,37(2180,74 ; 31121,47)^{\# 0}$ \\
\hline & через 7 суток & $5,12(4,47 ; 5,75)^{0}$ & $77,55(60,03 ; 92,63)^{0}$ & $50,70(38,03 ; 61,38)^{\# 0}$ & $2917,37(1823,94 ; 4287,75)^{\ddagger 0}$ \\
\hline & через 30 суток & $8,90(7,82 ; 9,87)^{\# 0}$ & $49,15(39,80 ; 56,05)^{\#}$ & $30,15(20,60 ; 36,10)^{\#}$ & $1127,43(658,19 ; 1591,63)^{*}$ \\
\hline \multirow{3}{*}{$\begin{array}{l}\text { Группа 4: животные } \\
\text { с экспериментальным } \\
\text { гипотиреозом }\end{array}$} & через 1 сутки & $3,47(3,03 ; 3,90)^{1 *}$ & $65,25(46,43 ; 88,98)^{*}$ & $45,05(31,98 ; 56,28)^{\star}$ & $2409,08(1196,19 ; 3843,20)^{*}$ \\
\hline & через 7 суток & $4,19(3,84 ; 4,66)^{1 \star}$ & $47,75(40,65 ; 54,38)^{1 *}$ & $33,65(27,53 ; 44,78)^{*}$ & $1182,59(851,75 ; 1943,46)^{1 \star}$ \\
\hline & через 30 суток & $5,87(4,81 ; 6,85)^{1 *}$ & $40,00(31,15 ; 50,00)^{1 *}$ & $24,45(20,25 ; 29,73)^{1 *}$ & $779,69(506,25 ; 1086,82)^{1 *}$ \\
\hline \multirow{3}{*}{$\begin{array}{l}\text { Группа 5: животные с } \\
\text { экспериментальным } \\
\text { гипотиреозом, } \\
\text { суммарная плотность } \\
\text { дозы } 112 \text { Дж/см² }\end{array}$} & через 1 сутки & $7,76(6,81 ; 8,63)^{\star 0}$ & $40,50(31,40 ; 52,83)^{\star 0}$ & $22,60(16,28 ; 28,93)^{* 0}$ & $734,71(423,79 ; 1153,31)^{\star 0}$ \\
\hline & через 7 суток & $11,00(9,73 ; 12,40)^{\star 0}$ & $44,70(33,83 ; 59,60)^{0}$ & $27,10(20,68 ; 31,20)^{* 0}$ & $898,41(623,40 ; 1390,14)^{* 0}$ \\
\hline & через 30 суток & $7,63(7,00 ; 8,27)^{\star 0}$ & $37,75(29,48 ; 44,35)^{0}$ & $21,50(18,93 ; 25,05)^{\star 0}$ & $656,24(464,05 ; 865,92)^{0}$ \\
\hline \multirow{3}{*}{$\begin{array}{l}\text { Группа 6: животные с } \\
\text { экспериментальным } \\
\text { гипотиреозом, } \\
\text { суммарная плотность } \\
\text { дозы } 450 \text { Дж/см² }\end{array}$} & через 1 сутки & $6,23(5,43 ; 7,33)^{\star 0}$ & $207,00(95,53 ; 344,00)^{* 0}$ & $163,00(58,35 ; 233,25)^{\star 0}$ & $28338,69(4115,17 ; 61410,05)^{* 0}$ \\
\hline & через 7 суток & $4,45(4,06 ; 4,96)^{* 0}$ & $73,85(49,08 ; 91,68)^{0 *}$ & $42,70(36,45 ; 61,58)^{* 0}$ & $2504,98(1466,21 ; 4167,30)^{* 0}$ \\
\hline & через 30 суток & $6,06(5,25 ; 6,77)^{0}$ & $47,55(40,48 ; 59,48)^{* 0}$ & $24,70(22,10 ; 30,18)^{0}$ & $979,59(693,59 ; 1278,27)^{\star 0}$ \\
\hline
\end{tabular}

Примечание: ${ }^{1} p<0,05$ при сравнении группы контроля с группой гипотиреоза; ${ }^{p}<<0,05$ при сравнении групп лазерного воздействия с группой интактного контроля; ${ }^{*} p<0,05$ при сравнении групп лазерного воздействия с группой гипотиреоза; ${ }^{p} p<0,05$ при сравнении групп лазерного воздействия.

Таблица 2. Сравнительная характеристика групп животных по ядерно-клеточному отношению и индексу Брауна

\begin{tabular}{|c|c|c|c|}
\hline \multicolumn{2}{|l|}{ Группы } & Ядерно-клеточное отношение & Индекс Брауна \\
\hline \multicolumn{2}{|l|}{ Группа 1: интактные животные } & $32,78(29,25 ; 34,43)^{\# 1}$ & $4,76(3,76 ; 6,72)^{\# 1}$ \\
\hline \multirow{3}{*}{ Группа 2: интактные животные, суммарная плотность дозы 112 Дж/см² } & через 1 сутки & $49,04(42,99 ; 55,35)^{\# 0}$ & $2,95(2,42 ; 3,46)^{\# 0}$ \\
\hline & через 7 суток & $40,04(32,39 ; 43,18)$ & $2,94(2,54 ; 3,56)^{\# 0}$ \\
\hline & через 30 суток & $36,19(32,07 ; 43,72)^{0}$ & $4,37(3,62 ; 4,97)^{0}$ \\
\hline \multirow{3}{*}{ Группа 3: интактные животные, суммарная плотность дозы 450 Дж/см² } & через 1 сутки & $30,02(25,54 ; 35,62)^{0}$ & $3,50(3,31 ; 6,79)^{0}$ \\
\hline & через 7 суток & $36,49(26,44 ; 46,73)$ & $5,97(4,78 ; 7,02)^{\# 0}$ \\
\hline & через 30 суток & $31,66(25,76 ; 36,63)^{0}$ & $2,49(2,20 ; 2,89)^{\# 0}$ \\
\hline \multirow{3}{*}{ Группа 4: животные с экспериментальным гипотиреозом } & через 1 сутки & $14,90(13,17 ; 21,21)^{1 *}$ & $8,04(5,74 ; 9,49)^{1 *}$ \\
\hline & через 7 суток & $23,67(18,92 ; 26,45)^{1 *}$ & $4,72(4,06 ; 5,95)^{*}$ \\
\hline & через 30 суток & $23,79(20,75 ; 29,64)^{1}$ & $2,74(2,21 ; 3,28)^{1 *}$ \\
\hline \multirow{3}{*}{$\begin{array}{l}\text { Группа 5: животные с экспериментальным гипотиреозом, суммарная } \\
\text { плотность дозы } 112 \text { Дж/см² }\end{array}$} & через 1 сутки & $29,82(26,26 ; 36,28)^{*}$ & $2,46(2,10 ; 2,90)^{* 0}$ \\
\hline & через 7 суток & $29,08(27,24 ; 37,89)^{\star 0}$ & $1,71(1,39 ; 2,05)^{\star 0}$ \\
\hline & через 30 суток & $25,87(22,42 ; 32,37)$ & $2,06(1,92 ; 2,39)^{\star 0}$ \\
\hline \multirow{3}{*}{$\begin{array}{l}\text { Группа 6: животные с экспериментальным гипотиреозом, суммарная } \\
\text { плотность дозы } 450 \text { Дж/см² }\end{array}$} & через 1 сутки & $30,18(22,63 ; 31,87)^{\star}$ & $5,69(4,64 ; 8,50)^{0}$ \\
\hline & через 7 суток & $25,51(19,50 ; 29,03)^{0}$ & $4,76(4,23 ; 6,02)^{0}$ \\
\hline & через 30 суток & $27,33(23,31 ; 33,10)$ & $2,93(2,57 ; 3,23)^{0}$ \\
\hline
\end{tabular}

Примечание: ${ }^{1} p<0,05$ при сравнении группы контроля с группой гипотиреоза; ${ }^{p}<$ < 0,05 при сравнении групп лазерного воздействия с группой интактного контроля; * $p<0,05$ при сравнении групп лазерного воздействия с группой гипотиреоза; ${ }^{\circ} p<0,05$ при сравнении групп лазерного воздействия. 
соответственно, иногда с признаками пролиферации и десквамации. Бледно-голубого цвета коллоид с признаками краевой вакуолизации тесно прилегал к стенке фолликула. Присутствовали интерфолликулярные островки. При данном режиме лазерного воздействия мы отмечали статистически значимое повышение высоты эпителия на всех сроках и уменьшение значений остальных изучаемых показателей: минимального диаметра фолликулов на всех сроках, максимального диаметра через 1 сутки и площади фолликулов через 1 и 30 суток. Индекс Брауна достоверно уменьшался на всех сроках наблюдения, а ядерно-клеточное отношение повышалось на ранних сроках (1 и 7 сутки).

Через сутки после воздействия на щитовидную железу животных с экспериментальным гипотиреозом лазером в дозе 450 Дж/см² в строме органа наблюдали резко выраженное паретическое полнокровие сосудов всех калибров с явлениями эритростазов, сладжированием эритроцитов и мелкими диапедезными периваскулярными кровоизлияниями, умеренный отек межуточной ткани. Фолликулы во всех полях зрения были неправильной формы, вытянутые, нередко имели складчатые стенки. Тиреоциты находились в состоянии тяжелой белковой дистрофии вплоть до некробиозов и некрозов, отдельные группы клеток были десквамированы в просвет фолликулов. Коллоид в некоторых фолликулах лежал пристеночно, имел мелкозернистую структуру, просветы других фолликулов заполнены пластами десквамированных клеток, просветы единичных фолликулов практически пусты. Через 7 суток после облучения в строме железы сохранялось венознокапиллярное полнокровие с картиной эритростазов. Фолликулы были преимущественно округлой формы, тиреоциты - в состоянии диспротеиноза разной степени выраженности (рис. 4). В сравнении с предыдущим сроком исследования (1 сутки) наличие десквамированных тиреоцитов наблюдали в единичных фолликулах. Коллоид в виде бледноокрашенной полоски в большинстве

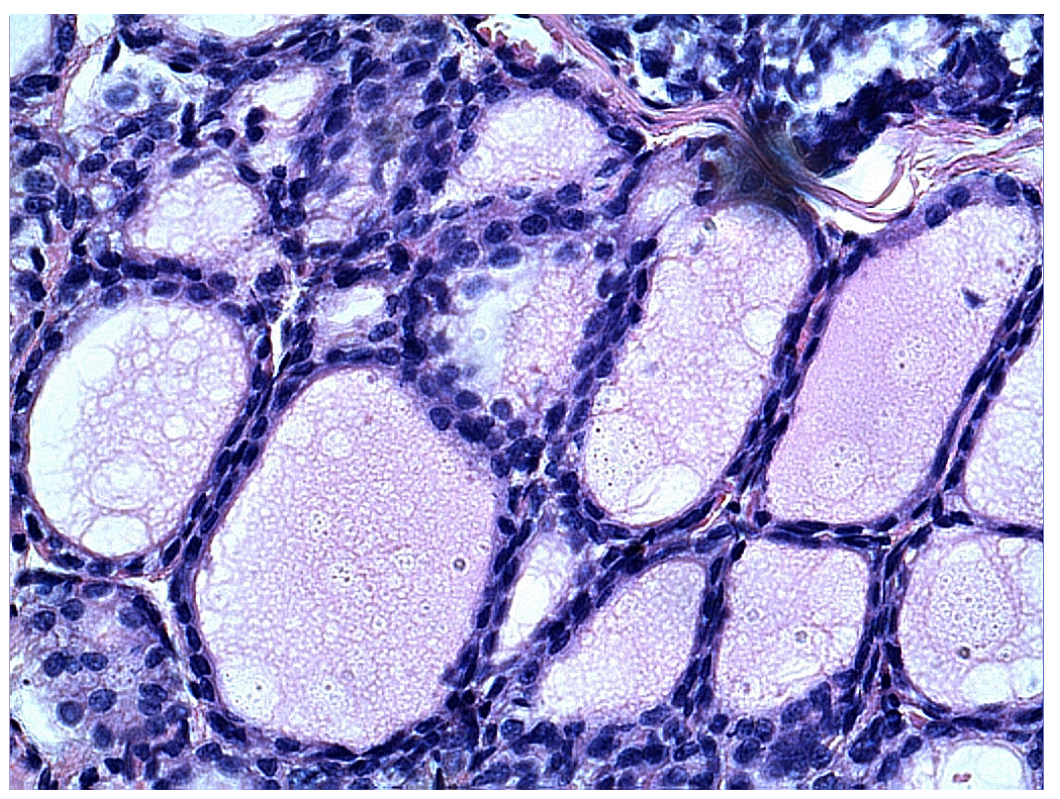

Рис. 3. Результаты лазерного воздействия дозой 112 Дж/см² на животных с экспериментальным гипотиреозом через 7 суток. Окраска: гематоксилинэозин; ув. $\times 400$

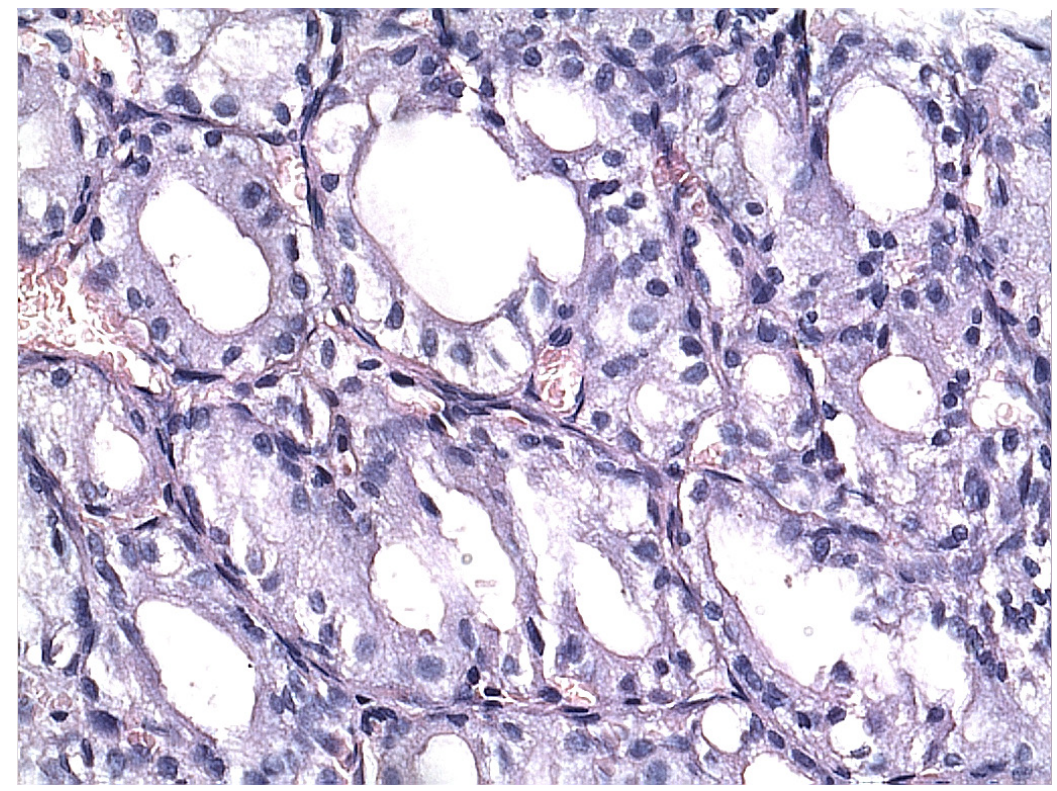

Рис. 4. Результаты лазерного воздействия дозой 450 Дж/см² на животных с экспериментальным гипотиреозом через 7 суток. Окраска: гематоксилинэозин; ув. $\times 400$ 
фолликулов лежал пристеночно. Через 30 суток после данного лазерного воздействия полнокровие стромы сохранялось. Тиреоциты имели преимущественно кубическую форму с признаками диспротеиноза разной степени в некоторых полях зрения. Очертания фолликулов ровные округлые или овальные, просвет большей части коллоида пустой. В единичных полях зрения фолликулы были заполнены бледноокрашенным коллоидом с примесью небольшого количества десквамированных тиреоцитов.

\section{ОБСУЖДЕНИЕ РЕЗУЛЬТАТОВ}

Структурно-функциональной единицей щитовидной железы традиционно считают фолликул - пузыревидное образование с полостью внутри. У здоровых крыс фолликулы имеют преимущественно округлую или овальную форму и равномерно распределены по всей паренхиме железы. Стенка фолликула выстлана однослойным эпителием, состоящим из фолликулярных эндокриноцитов (тиреоцитов). Полость фолликула заполнена продуктом секреции тиреоцитов - коллоидом. В зависимости от функционального состояния железы высота эпителия, форма и объем фолликулов изменяются. Так, в нормальных условиях тиреоциты имеют форму куба, а процессы образования и резорбции коллоида уравновешены. При гипофуннции щитовидной железы эпителий уплощается, фолликулы обычно увеличиваются в размерах. При гиперфункции тиреоциты становятся цилиндрическими, объем фолликулов уменьшается за счет резорбции коллоида. Степень функциональной активности эпителия щитовидной железы отражают показатели ядерно-клеточного отношения (возрастает с увеличением активности) и индекса Брауна (снижается при усилении активности).

Уменьшение ядерно-клеточного отношения, высоты тиреоидного эпителия и увеличение индекса Брауна, а также площади фолликулов через сутки после моделирования гипотиреоза свидетельствует о снижении функциональной активности щитовидной железы и подтверждается изменением содержания гормонов в сыворотке крови, полученным нами ранее [12]. Через 7 и 30 суток наблюдения животных с моделью гипотиреоза мы отмечали постепенное повышение высоты эпителия, ядерно-клеточного отношения и уменьшение диаметров, площади фолликулов, индекса Брауна, что характерно для восстановления функции щитовидной железы.

Изменения, наблюдаемые нами при лазерном облучении щитовидной железы интактных животных при суммарной плотности дозы с поверхности кожи, равной 112 Дж/см², мы объясняем стимулирующим действием лазера, запуском каскада реакций на клеточном уровне, способствующим улучшению микроциркуляции ткани железы, активации ангиогенеза.

Эффекты лазера реализуются при поглощении фотонов соответствующими длине волны лазера мембранными хромофорами с последующим изменением окислительновосстановительных процессов клетки и изменением проницаемости кальциевых каналов [13, 14].

По данным литературы одним из эффектов лазерного воздействия является изменение микроциркуляции органа в результате процессов, связанных с локальным синтезом оксида азота [3, 6]. Активация кровотока щитовидной железы после лазерного облучения способствует синтезу гормонов тиреоидным эпителием [10, 15, 16].
Выраженные изменения значений анализируемых показателей щитовидной железы интактных животных после облучения лазером при суммарной плотности дозы с поверхности кожи, равной 450 Дж/см², мы объяснили более жестким воздействием облучения [17]. Применение высоких доз лазера могло являться активатором оксидативного стресса и вызывать необратимые изменения мембранных и структурных клеточных белков [18].

После окончания лазерного воздействия в дозе 112 Дж/см² на щитовидную железу животных с моделью гипотиреоза увеличение высоты эпителия, ядерно-клеточного отношения и уменьшение диаметров и площади фолликулов, а также индекса Брауна было более выражено на ранних сроках наблюдения (1 и 7 сутки), что позволяет говорить о стимулирующем воздействии данной дозы облучения на функциональную активность органа при гипотиреозе и характеризует регенеративные процессы, направленные на восстановление структуры щитовидной железы после повреждающего действия тиреостатика. По данным нашего предыдущего исследования [12] снижение концентрации тиреотропного гормона (ТТГ), увеличение свободной и связанной фракций Т4 и Т3 также позволяют говорить о стимулирующем воздействии лазерного облучения в дозе 112 Дж/см² на щитовидную железу при гипотиреозе.

Изменение анализируемых показателей после воздействия на щитовидную железу животных с экспериментальным гипотиреозом лазером в дозе 450 Дж/см² наряду с морфологической картиной и снижением содержания гормонов, по ранее опубликованным результатам, позволяет сделать вывод об ослаблении функции железы.

При анализе полученных результатов после лазерного воздействия выявлено увеличение всех изучаемых показателей, статистически значимое для высоты эпителия и минимального диаметра фолликулов на ранних сроках (1 и 7 сутки), а для максимального диаметра и площади фолликулов на всех сроках наблюдения. Достоверное повышение ядерноклеточного отношения наблюдалось через 1 сутки после облучения.

При сравнении двух изучаемых режимов лазерного воздействия на группу интактных животных, оказалось, что высота эпителия была достоверно больше на ранних сроках (1 и 7 сутки) и меньше через 30 суток при лазерном воздействии в дозе 112 Дж/см². Показатели максимального, минимального диаметра и площади фолликулов на сроках наблюдения 1 и 7 суток уменьшались. Индекс Брауна был меньше на ранних сроках наблюдения (1 и 7 сутки) и больше через 30 суток. Ядерно-клеточное отношение больше через 1 и 30 суток.

Сравнение двух изучаемых режимов лазерного воздействия на группу животных с экспериментальным гипотиреозом показало, что воздействие в дозе 450 Дж/см² вызывает достоверное снижение высоты тиреоидного эпителия и увеличение остальных изучаемых показателей на всех сроках исследования. Также повышался индекс Брауна. Статистически значимо уменьшалось ядерно-клеточное отношение через 7 суток наблюдения.

Согласно полученным результатам, воздействие лазера на щитовидную железу характеризуется дозозависимым эффектом с проявлением стимуляции функциональной активности щитовидной железы при суммарной плотности дозы 112 Дж/см², более выраженным на ранних сроках (1 и 7 сутки), и торможением ее активности при дозе 450 Дж/ $\mathrm{CM}^{2}$. 


\section{ВЫВОДЬ}

Воздействие лазерного излучения средней интенсивности приводит к достоверным изменениям морфофункционального состояния фолликулов щитовидной железы крыс как в норме, так и при экспериментальном гипотиреозе.

Стимулирующее влияние инфракрасного лазерного воздействия с суммарной плотностью дозы 112 Дж/см² на щитовидную железу крыс-самцов с явлениями гипотиреоза более выражено на ранних сроках наблюдения (1 и 7 сутки), тогда как при дозе 450 Дж/см² наблюдаются тормозящие эффекты на всех сроках наблюдения.

Учитывая полученные нами результаты, использование лазерного инфракрасного воздействия с плотностью дозы 112 Дж/см² на поверхности кожи можно считать предпочтительным для изучения возможностей терапии гипотиреоза в эксперименте.

\section{Литература}

1. Абдулхабирова Ф. М. Гипотиреоз и беременность. Поликлиника. 2014; 5: 16-18.

2. Пузин Д. А., Аристархов В. Г., Аристархов Р. В., Квасов А. В. Применение низкоинтенсивной лазеротерапии в лечении субклинического гипотиреоза различной этиологии. Лазерная медицина. 2017; 21 (1): 11-14.

3. Москвин С. В. Эффективность лазерной терапии. Серия «Эффективная лазерная терапия». М.: Издательство «Тверь»; 2015 (2).

4. Кравченко Т. Г., Зарезина А. С., Головнева Е. С. Оценка глубины проникновения лазерного излучения при терапевтическом воздействии методом компьютерного моделирования. Вестник новых медицинских технологий. 2007; 14 (2): 202-4.

5. Кравченко Т. Г., Кудрина М. Г., Гужина А. О., Попов Г. К., Головнева Е. С. Локальные эффекты системного лазерного облучения повышенной мощности. Вестник уральской академической науки. 2012; 2 (39): 126-27.

6. Hofling DB, Chavantes MC, Juliano AG, Cerri GG, Knobel M, Yoshimura EM, et al. As sessment of the effects of low-level laser therapy on the thyroid vascularization of patients with autoimmune hypothyroidism by color Doppler ultrasound. ISRN Endocrinol. 2012 Dec 17: 1-9. PubMed PMID: 23316383.

7. Hofling DB, Chavantes MC, Acencio MM, et. al. Effects of low-level laser therapy on the serum TGF- $\beta$ concentrations in individuals with autoimmune thyroiditis. Laser Surg. 2014; 32 (8): 444-49.

8. Morcos N, Omran M, Ghanem H, Elahdal M, Kamel N, Attia E. Phototherapeutic Effect of Low-Level Laser on Thyroid Gland of Gamma-Irradiated Rats. J Photobiol. 2015; 91 (4): 942-51.

9. Weber JB, Mayer L, Cenci RA, et al. Effect of three different protocols of low-level laser therapy on thyroid hormone production after dental implant placement in an experimental rabbit model. Laser Surg. 2014; 32 (11): 612-17.

10. Аристархов В. Г. Рекомендации по применению инфрракрасного

\section{References}

1. Abdulkhabirova FM. Gipotireoz i beremennost'. Poliklinika. 2014; 5: 16-18. Russian.

2. Puzin DA, Aristarkhov VG, Aristarkhov RV, Kvasov AV. Primenenie nizkointensivnoy lazeroterapii $v$ lechenii subklinicheskogo gipotireoza razlichnoy etiologii. Lazernaya meditsina. 2017; 21 (1): 11-14. Russian.

3. Moskvin SV. Effektivnost' lazernoy terapii. Seriya «Effektivnaya lazernaya terapiya». M.: Izdatelstvo «Tver'»; 2015 (2). Russian.

4. Kravchenko TG, Zarezina AS, Golovneva ES. Otsenka glubiny proniknoveniya la-zernogo izlucheniya pri terapevticheskom vozdeystvii metodom komp'yuternogo modeliro-vaniya. Vestnik novykh meditsinskikh tekhnologiy. 2007; 14 (2): 202-4. Russian.

5. Kravchenko TG, Kudrina MG, Guzhina AO, Popov GK, Golovneva ES Lokal'nye effekty sistemnogo lazernogo oblucheniya povyshennoy moshchnosti. Vestnik ural'skoy akademicheskoy nauki. 2012; 2 (39): 126-7. Russian.

6. Hofling DB, Chavantes MC, Juliano AG, Cerri GG, Knobel M, Yoshimura EM, et al. Assessment of the effects of low-level laser

therapy on the thyroid vascularization of patients with autoimmune hypothyroidism by color Doppler ultrasound. ISRN Endocrinol. 2012 Dec 17: 1-9. PubMed PMID: 23316383.

7. Hofling DB, Chavantes MC, Acencio MM, et al. Effects of low-level laser therapy on the serum TGF- $\beta$ concentrations in individuals with autoimmune thyroiditis Laser Surg. 2014; 32 (8): 444-49.

8. Morcos N, Omran M, Ghanem H, Elahdal M, Kamel N, Attia E. Phototherapeutic Effect of Low-Level Laser on Thyroid Gland of Gamma-Irradiated Rats. J Photobiol. 2015; 91 (4): 942-51.

9. Weber JB, Mayer L, Cenci RA, et al. Effect of three different protocols of low-level laser therapy on thyroid hormone production after dental implant placement in an experimental rabbit model. Laser Surg. 2014; 32 (11): 612-17.

10. Aristarkhov VG. Rekomendatsii po primeneniyu infrakrasnogo lazernogo izlucheniya $u$ bol'nykh $s$ patologiey shchitovidnoy zhelezy. V sbornike: Materialy nauchno-prakticheskoy konferentsii GBOU VPO RyazGMU Minzdrava Rossii; 2014 g.; Ryazan'. RIO RyazGMU 2014. Russian. 


\section{ORIGINAL RESEARCH I ENDOCRINOLOGY}

11. Isman CA, Yegen BC, Alican I. Methimazole-induced hypothyroidism in rats ameliorates oxidative injury in experimental colitis. J Endocrinol. 2003; 177 (3): 471-76.

12. Smelova IV, Golovneva ES. Dinamika funktsional'noy aktivnost tireotsitov pri izmenenii morfofunktsional'nogo sostoyaniya tuchnykh kletok shchitovidnoy zhelezy pod vozdeystviem infrakrasnogo lazernogo izlucheniya. Vestnik RGMU. 2016; 6: 39-44.

13. Chaves ME, Araujo AR, Piancastelli AC, et al. Effects of lowpower light therapy on wound healing: LASER $x$ LED. An Bras Dermatol. 2014; 89 (4): 616-23.

14. Zalesskiy VN. K 50-letiyu lazernoy meditsiny: molekulyarnye mekhanizmy lazernoy biostimulyatsii. Ukrainskiy meditsinskiy zhurnal. 2010; 5 (79): 52-58.
15. Pinheiro AL, Browne RM, Frame JW, et al. Mast cells in laser and surgical wounds. Braz Dent J. 1995; 6 (1): 11-16.

16. Kozel Al, Solovyeva LI, Popov GK. K mekhanizmu deystviya nizkointensivnogo lazernogo izlucheniya na kletku. Byulleten' eksperimental'noy biologii i meditsiny. 1999; 128 (10): 397-399.

17. Golovneva ES, Shakirov NN, Kravchenko TG, Omelyanenko AG, Popova IA. Vliyanie mnogokratnogo infrakrasnogo lazernogo oblucheniya zon lokalizatsii krasnogo kostnogo mozga na pokazateli eritrotsitarnogo zvena perifericheskoy krovi. Lazernaya meditsina. 2013; 17 (4): 33-35.

18. Sun $X$, Wu S, Xing D. The reactive oxygen species-Src-Stat3 pathway provokes negative feedback inhibition of apoptosis induced by high-fluence low-power laser irradiation. FEBS J. 2010; 277 (22): 4789-802. 